\title{
Fuzzy Controller Design Using FPGA for Sun and Maximum Power Point Tracking in Solar Array System
}

\author{
Basil M. Hamed and Mohammed S. El-Moghany
}

\begin{abstract}
In this paper, Two fuzzy logic controllers are fabricated on modern FPGA card (Spartan-3AN, Xilinx Company, 2009) to increase the energy generation efficiency of solar cells. These controllers are, sun tracking controller and maximum power point tracking controller. Sun tracking generating power system is designed and implemented in real time. A tracking mechanism composed of photovoltaic module, stepper motor, sensors, input/output interface and expert FLC controller implemented on FPGA, that to track the sun and keep the solar cells always face the sun in most of the day time. The proposed sun tracking controller, and maximum power point tracking controller are tested using Matlab/Simulink program, Maximum power point tracking system is designed and implemented in real time. The results show that both controllers have a response better than conventional controller applied on the same system.
\end{abstract}

Index Terms-Fuzzy control, MPPT, sun tracking, photovoltaic system, FPGA.

\section{INTRODUCTION}

Solar panels are power sources in photovoltaic applications. Unfortunately, solar panels have high fabrication cost and low energy conversion efficiency. Since the photovoltaic electricity is expensive compared to the electricity from the utility grid, utilization of all accessible solar panels output power is desired. Therefore, the photovoltaic systems should be designed to operate at their maximum output power in any environmental conditions.

The applications for solar energy are increased, and that need to improve the materials and methods used to harness this power source [1]. The solar cell has an optimum operating point to be able to get the maximum power. To obtain maximum power from photovoltaic array, photovoltaic power system usually requires maximum power point tracking controller [2] and [3]. There are three major approaches for maximizing power extraction in solar systems. They are sun tracking, maximum power point tracking or both [4]. These methods need intelligent controllers such as fuzzy logic controller or conventional controller such as PID controller. In the literature, many maximum power point tracking systems have been proposed and implemented [5] and [6]. The fuzzy theory based on fuzzy sets and fuzzy algorithms provides a general method of expressing linguistic rules so that they may be processed quickly. The advantage of the fuzzy logic control is that it does not strictly need any mathematical model of the plant.

Manuscript received January 18, 2013; revised March 25, 2013

The authors are from Electrical Engineering Department Islamic University of Gaza, Gaza, Palestine (e-mail: bhamed@iugaza.edu, elmoghany@hotmail.com).
It is based on plant operator experience, and it is very easy to apply. Hence, many complex systems can be controlled without knowing the exact mathematical model of the plant [7]. In addition, fuzzy logic simplifies dealing with nonlinearities in systems [8]. The most popular method of implementing fuzzy controller is using a general-purpose microprocessor or microcontroller. Microprocessor based controllers are more economical, but often face difficulties in dealing with control systems that require high processing and input/output handling speeds [9]. Rapid advances in digital technologies have given designers the option of implementing a controller on a variety of Programmable Logic Device (PLD), Field Programmable Gate Array (FPGA), etc. FPGA is suitable for fast implementation controller and can be programmed to do any type of digital functions. FPGA has the ability to operate faster than a microprocessor chip. Because of the flexibility of the FPGA, additional functionality and user interface controls can be incorporated into the FPGA minimizing the requirement for additional external components [10]. The FPGAs can be programmed while they run, because they can be reprogrammed in the order of microseconds. This short time means that the system will not even sense that the chip was reprogrammed [11]. In the literature, many sun tracking systems have been proposed and implemented too [12]-[14].

This paper presents the hardware implementation of fuzzy logic controller (FLC) on FPGA for Photovoltaic MPPT. A significant advantage of this FLC is that it has been coded in VHDL and programmed into a single FPGA [15]. Because this reduces the number of electronic components used to implement the controller, it enables redundancy by having multiple copies/images of the code, and yields robustness as a controller that has multiple systems capability [16].The FLC may implement on FPGA and used to moves a motor attached to the solar panel to keep it toward the sun all the day. Then we must choose the kind of the motor as appropriate with the controlled system. Many applications related to positioning systems are being implemented with stepper motors. One of the main advantages of stepper motors is the strong relation between electrical pulses and rotation discrete angle steps [17].

\section{SUN TRACKER}

Solar tracking system uses a stepper motor as the drive source to rotate the solar panel as shown in Fig. 1. The position of the sun is determined by using a tracking sensor, the sensor reading is converted from analog to digital signal, and then it passed to a fuzzy logic controller implemented on FPGA. The controller output is connected to the driver of 
the stepper motor to rotate PV panel in one axis until it faces the sun.

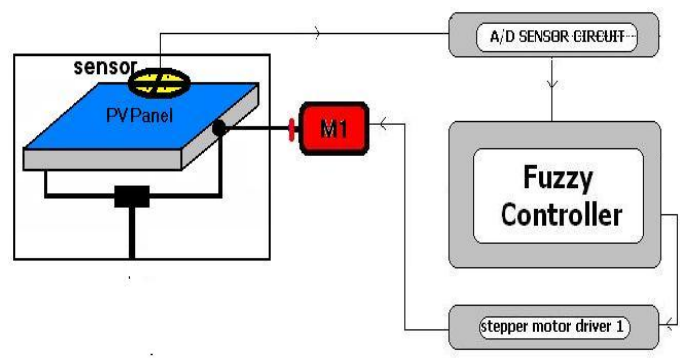

Fig. 1. Block diagram for the sun tracker system.

\section{A. Sensors}

There are two sensors used in the sun tracking system: photo sensor, and position sensor.

\section{1) Photo sensor}

Light dependent resistor (LDR) is used to construct the sensor. The tracking sensor is composed of two similar LDR sensors, which are located at the east, west, or south, and north to detect the light source intensity. The LDR sensor forms a $45^{\circ}$ angle with the light source. To sense the position of Sun in one axe say east/west, two LDR sensors are mounted on the solar panel and placed in an enclosure. It has a response which is similar to the human eye. The east and west LDR sensors compare the intensity of received light in the east and west. When sun's position shifts, here the light source intensity received by the sensors isdifferent; the system obtains signals from the sensors' output voltage in the two orientations. The system then determines which sensor received more intensive light based on the sensor output voltage value interpreted by voltage type $\mathrm{A} / \mathrm{D}$ converter. The system drives the step motor towards the orientation of this sensor. If the output values of the two sensors are equal, the output difference is zero and the motor's drive voltage is zero, which means the system has tracked the current position of the sun.

2) Position sensor

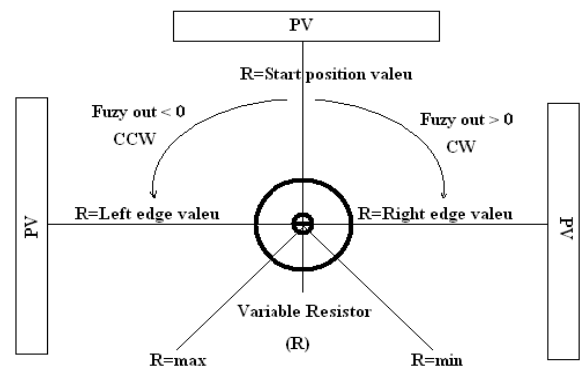

Fig. 2. Position sensor.

Position sensor used to determine the location of the PV panel to prevent the panel from the impact when it reaches the edges, and to get the PV panel to the starting point at the night. This sensor used a variable resistor (potentiometer) located on the rotor of the motor and rotate with it, and the value of the resistor $(\mathrm{R})$ varies with the rotation as shown in Fig. 2. When the position sensor reaches the values at the PV at the edges, the controller stopped the motor and immune it from rotating in that direction. At the night the LDRs sensors arevery dark light and their values are very big, in this situation the controller go to night subroutine to rotate the PV panel until the position sensor has the starting point value.

\section{B. Fuzzy Logic Controller}

FLC has been constructed and the block diagram in Fig. 3 shows the FLC for the sun tracker system.

\section{3) FLC Design}

FLC has two inputs which are: error and the change in error, and one output feeding to the stepper motor driver.

In this paper, Mamdani approach has been used to implement FLC for the sun tracker. FLC contains three basic parts: Fuzzification, Base rule, and Defuzzification.

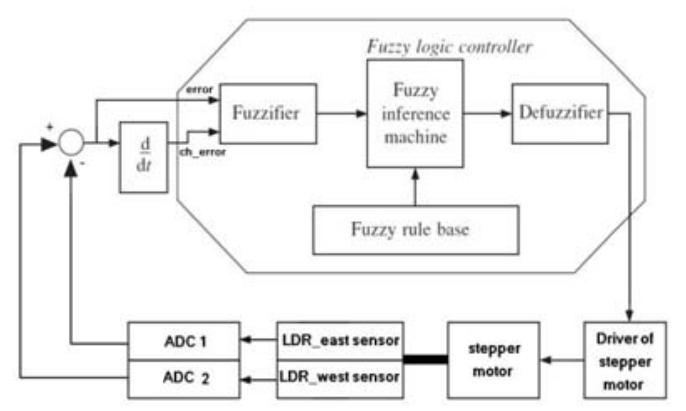

Fig. 3. FLC for the sun tracker system.

\section{4) Fuzzification}

Fig. 4 illustrates the fuzzy set of the Error input which contains 7 Triangular memberships

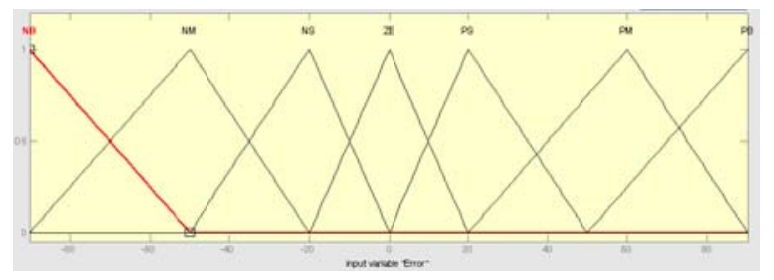

Fig. 4. Error fuzzy set of FLC.

Fig. 5 illustrates the fuzzy set of the Change of Error input which contains 7 Triangular memberships.

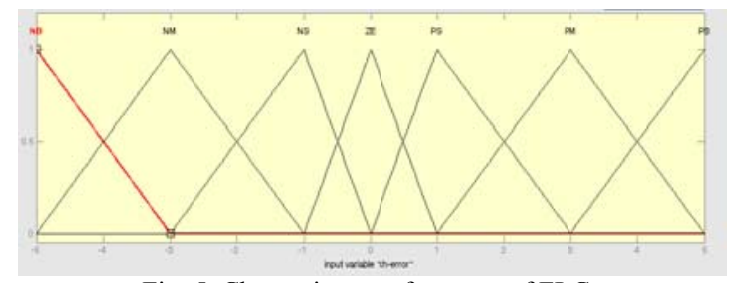

Fig. 5. Change in error fuzzy set of FLC.

Fig. 6 illustrates the fuzzy set of the output which contains 7 triangular memberships.

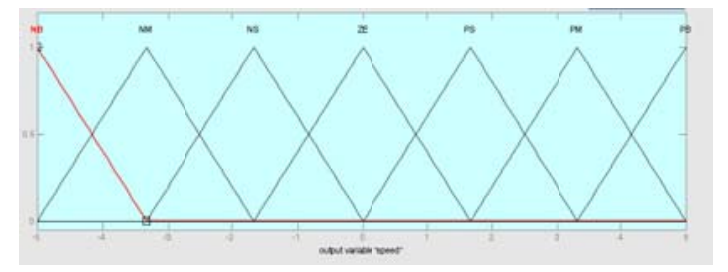

Fig. 6. Fuzzy set of FLC output entering to stepper motor driver. 


\section{5) Control rule base}

The knowledge base is definedby the rules for the desired relationship between the input and output variables in terms of the membership functions illustrated in Table I. The control rules are evaluated by an inference mechanism, and represented as a set of:

IF Error is ..and Change of Error is ... THEN the Output will ....

For example, Rule1: IF Error is NS and Change of Error is ZE THEN the output is NS.

The linguistic variables used are:

NB: Negative Big., NM: Negative Medium, .NS: Negative Small, ZE: Zero, PS: Positive Small, PM: Positive Medium, PB: Positive Big.

TABLE I: CONTROL Rule BASE For FuZzy CONTROLlER

\begin{tabular}{|c|c|c|c|c|c|c|c|}
\hline $\mathrm{Er} \backslash \mathrm{CE}$ & IIB & IIM & IIS & ZE & PS & PM & PB \\
\hline NB & $\mathrm{NB}$ & NB & NB & NB & NM & NS & ZE \\
\hline $\mathrm{NM}$ & $\mathrm{NB}$ & NB & NM & NMM & NS & ZE & PS \\
\hline NS & NB & NM & NS & NS & ZE & PS & $\mathrm{PM}$ \\
\hline ZE & NB & NM & NS & ZE & PS & $\mathrm{PM}$ & $\mathrm{PB}$ \\
\hline PS & NM & NS & ZE & PS & PS & $\mathrm{PM}$ & PB \\
\hline PM & NS & ZE & PS & PM & PM & PB & $\mathrm{PB}$ \\
\hline $\mathrm{PB}$ & ZE & PS & $\mathrm{PM}$ & $\mathrm{PB}$ & $\mathrm{PB}$ & PB & PB \\
\hline
\end{tabular}

\section{6) Defuzzification}

The centre of gravity method is widely used in Mamdani approach which has been selected in this paper to compute the output of the FLC, which is the motor speed as:

$$
\text { Speed }=\frac{\sum_{i=1}^{n} S_{i} \times \mu\left(S_{i}\right)}{\sum_{i=1}^{n} \mu\left(S_{i}\right)}
$$

7) Fuzzy logic controller simulation on matlab/simulink

Fig. 7 illustrates the Simulink block diagram for the Fuzzy controller for sun tracker system.

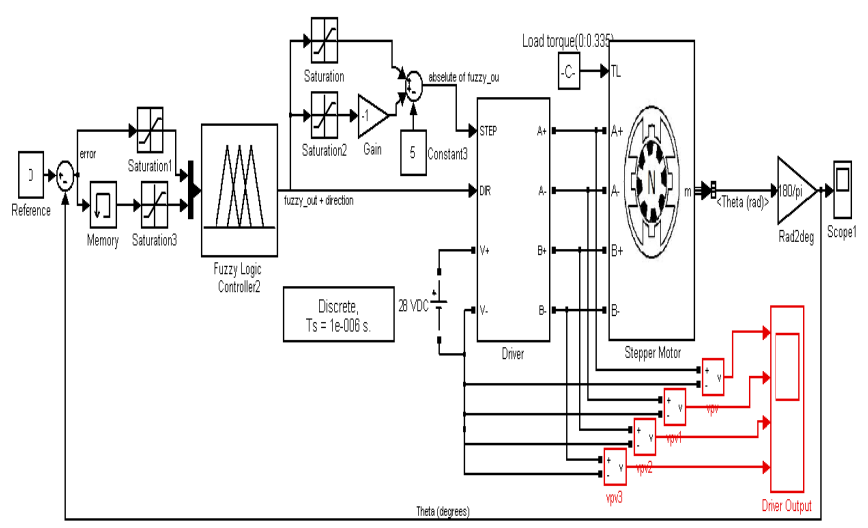

Fig. 7. Testing the FLC in the sun tracker system using matlab/simulink.

The controller has been tested using Simulink motor module in MATLAB, by applying the step input and initial degree of the rotor is -10 degree. The output step response is shown in Fig. 8. The range from -10 to 0 degree takes 5 steps since each step in our motor is 1.8 degree, so $(10 / 1.8)=$
5 steps.

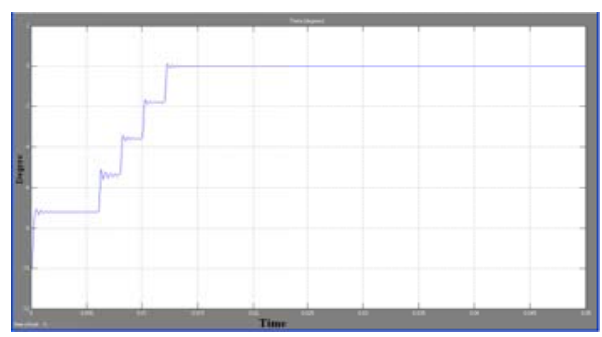

Fig. 8. Output degree

\section{8) Implementing fuzzy controller on FPGA}

The fuzzy logic controller designed earlier is implemented on Xilinx XC3S700AN FPGA card as shown in Fig. 9.

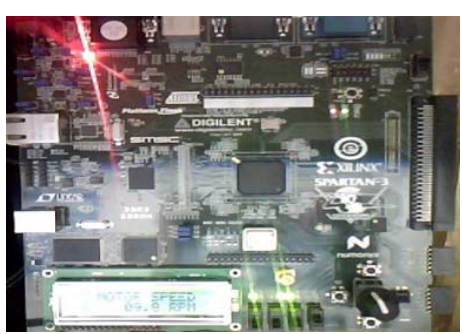

Fig. 9. FLC on FPGA card.

Fig. 10 shows the RTL schematic diagram in Xilinx software. The FLC appears as a red block, first input of the controller is error signal takes before differentiator (white block), and other input of the controller is change in error signal takes from after differentiator. The output of the controller is passed through three blocks, the first block which have green color to convert the crisp value to clock wave have a frequency appropriate with this value to control the speed of the motor, the second block which have blue color to extract the other motor control signal such the direction of the motor and the rotation enable signal, the third block which have yellow color (LcdTop block) is for LCD display screen to display the output of the controller. Other blocks are input/output data transfer.

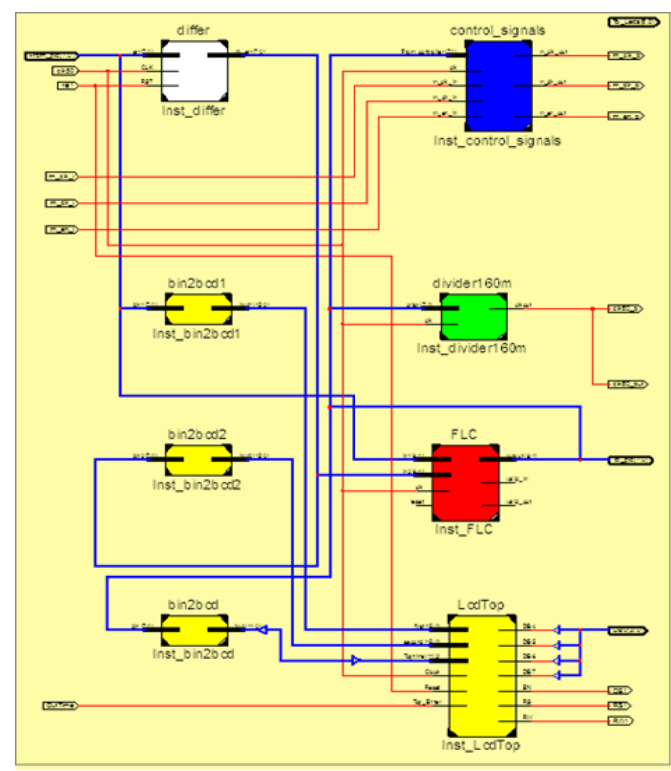

Fig. 10. RTL schematic diagram for the FLC with other blocks. 


\section{Mechanical Construction and Components}

System prototype is shown in Fig. 11 consists of a mechanical mechanism of 2 degrees of freedom (D.O.F) designed to support and direct a PV solar cell attached to it. Mechanism has the ability to rotate the PV cell about 2_axes, $x$ or $z$. But initially, we have locked $z$ - axis rotation and applied control scheme to $\mathrm{x}$ - axis only. Electromechanical drive system of $x$ - axis consists of a stepper motor with a $1.5 \mathrm{~cm}$ radius pulley attached to its shaft and is driving a $2.5 \mathrm{~cm}$ radius pulley attached to main driving shaft as shown in Fig. 14, through a belt. Belt mechanism realizes a speed reduction of $40 \%((1-1.5 / 2.5) \times 100)$, and a torque increase of $40 \%$ in order to with stand demand load. Main driving shaft, shown in Fig. 11 is attached to the main frame and supported with two bearings. Also, this shaft is provided by an electro-mechanical clutch in order to prevent axis rotation when driving motor is disabled and to assure to keep the PV panel at the same end position. Main driving shaft transmits rotation to the second shaft, shown in Fig. 11, through two identical meshing gears with the same angular speed. Second shaft is supported by the main frame by two ball bearings. PV panel is attached to the second shaft and its angular position is measured with a potentiometer attached to the second shaft end.

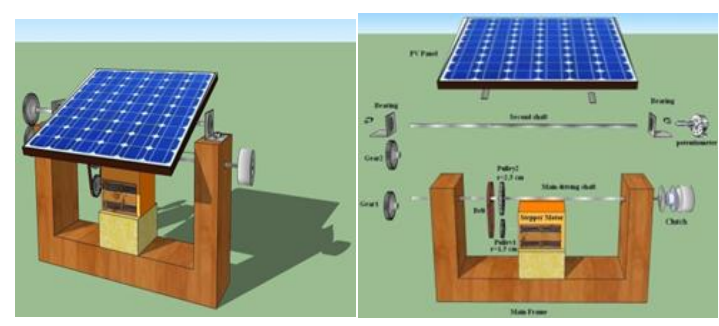

Fig. 11. System prototype.

\section{MPPT}

In this section, in order to show the feasibility of MPPT using fuzzy control, the photovoltaic power system with step down converter is constructed. The circuit configuration of this system is shown, and then the fundamental characteristics of solar array using this system are also shown in this section.

\section{A. Circuit Configuration}

From the solid-state physics point of view, the cell is basically a large area $\mathrm{p}-\mathrm{n}$ diode with the junction positioned close to the top surface [18]. So an ideal solar cell may be modeled by a current source in parallel with a diode that mathematically describes the I-V characteristic by [19]:

$$
I=I_{p v, \text { cell }}-I_{d}=I_{p v, \text { cell }}-I_{0, \text { cell }}\left[\exp \left(\frac{q V}{a k T}\right)-1\right]
$$

where $I_{p v}$, cell is the current generated by the incident light, $I_{d}$ is the Shockley diode equation, $I_{0}$, cell is the reverse saturation or leakage current of the diode, $\mathrm{q}$ is the electron charge [1.60217646*10-19C], $\mathrm{k}$ is the Boltzmann constant $[1.3806503 * 10-23 \mathrm{~J} / \mathrm{K}], \mathrm{T}[\mathrm{K}]$ is the temperature of the $\mathrm{p}-\mathrm{n}$ junction, and a is the diode ideality constant. A shunt resistance and a series resistance component are added to the model since no solar cell is ideal in practice [20].

Additional parameter is added to the basic equation to represent practical arrays are composed of several connected photovoltaic cells and equation 1 becomes as [19]:

$$
I=I_{p v}-I_{0}\left[\exp \left(\frac{V+R_{S} I}{V_{t} a}\right)-1\right]-\left(\frac{V+R_{S} I}{R_{p}}\right)
$$

where $I_{p v}$ and $I_{0}$ are the photovoltaic and saturation currents of the array and $\mathrm{V}_{\mathrm{t}}=\mathrm{NskT} / \mathrm{q}$ is the thermal voltage of the array with Ns cells connected in series Rs and Rp is the equivalent series and parallel resistance. Figure 12shows the I-V curve from equation 2 [19].

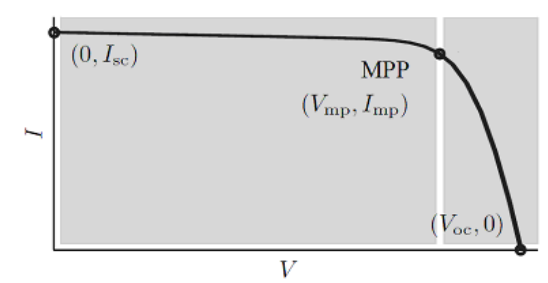

Fig. 12. Characteristic I-V curve of a practical photovoltaic device.

The light generated current of the photovoltaic cell Ipv and saturation current $\mathrm{I}_{0}$ depend on the temperature according to the following equations [19]:

$$
\begin{aligned}
& I_{p v}=\left(I_{p v, n}+K_{I} \Delta_{T}\right) \\
& I_{o}=\frac{I_{s c, n}+K_{I} \Delta_{T}}{\exp \left(\frac{V_{o c, n}+K_{V} \Delta_{T}}{a V_{t}}\right)-1}
\end{aligned}
$$

$I_{p v}, \quad n$ is the light-generated current at the nominal condition

\section{B. Output Characteristic of Photovoltaic Array}

A typical characteristic curve of PV model's current and voltage curve is shown in Fig. 12, and the power and voltage curve is shown in Fig. 13.

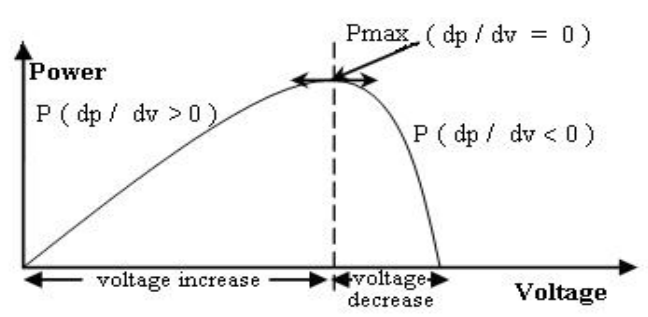

Fig. 13. Power-voltage characteristic of a PV module.

MPPT is used for extracting the maximum power from the solar PV module and transferring that power to the load. A $\mathrm{dc} / \mathrm{dc}$ (step up/step down) converter acts as an interface between the load and the module. The MPPT is changing the duty cycle to keep the transfer power from the solar PV module to the load at maximum point [21]. 


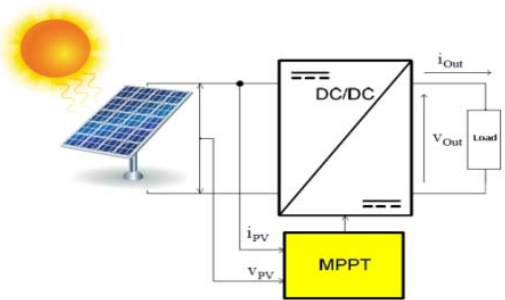

Fig. 14. Photovoltaic with MPPT system.

\section{FUZZY CONTROL OF MPPT}

\section{A. MPPT of PV Using Fuzzy Controller:}

MPPT system uses dc to dc converter to compensate the output voltage of the solar panel to keep the voltage at the value which maximizes the output power. MPP fuzzy logic controller measures the values of the voltage and current at the output of the solar panel, then calculates the power from the relation $\left(\mathrm{P}=\mathrm{V}^{*} \mathrm{I}\right)$ to extract the inputs of the controller. The crisp output of the controller represents the duty cycle of the pulse width modulation to switch the dc to $\mathrm{dc}$ converter.

\section{B. MPPT Fuzzy Logic Controller:}

The FLC examines the output PV power at each sample (time_k), and determines the change in power relative to voltage $(\mathrm{dp} / \mathrm{dv})$. If this value is greater than zero the controller change the duty cycle of the PWM to increase the voltage until the power is maximum or the value $(\mathrm{dp} / \mathrm{dv})=0$, if this value less than zero the controller changes the duty cycle of the PWM to decrease the voltage until the power is maximum as shown in Fig. 13. FLC has two inputs which are: error and the change in error, and one output feeding to the pulse width modulation to control the DC-to-DC converter. The two FLC inputs variables is defined by:

$$
\operatorname{Error}(k)=\frac{P(k)-P(k-1)}{V(k)-V(k-1)}
$$

$$
\text { Change_Error }(k)=\operatorname{Error}(k)-\operatorname{Error}(k-1)
$$

where, $\mathrm{P}(\mathrm{k})$ is the instant power of the photovoltaic generator. The input error $(\mathrm{k})$ shows if the load operation point at the instant $\mathrm{k}$ is located on the left or on the right of the maximum power point on the PV characteristic, while the input $\mathrm{CE}(\mathrm{k})$ expresses the moving direction of this point. The fuzzy inference is carried out by using Mamdani method. FLC contains three basic parts: Fuzzification, Base rule, and Defuzzification.

\section{1) Fuzzification}

Fig. 15 illustrates the fuzzy set of the Error input which contains 7 Triangular memberships.

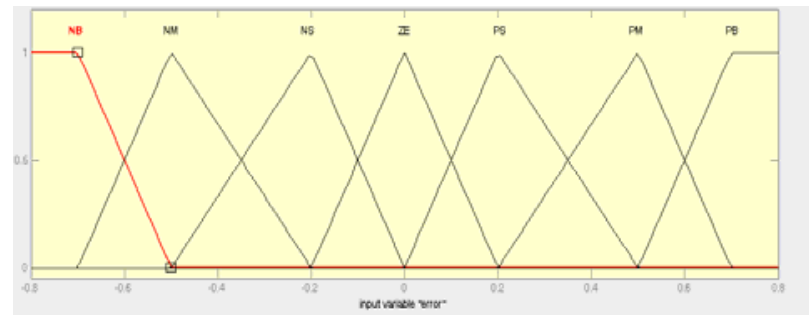

Fig. 15. Membership function of error (E).
Fig. 16 illustrates the fuzzy set of the Change of Error input which contains 7 Triangular memberships.

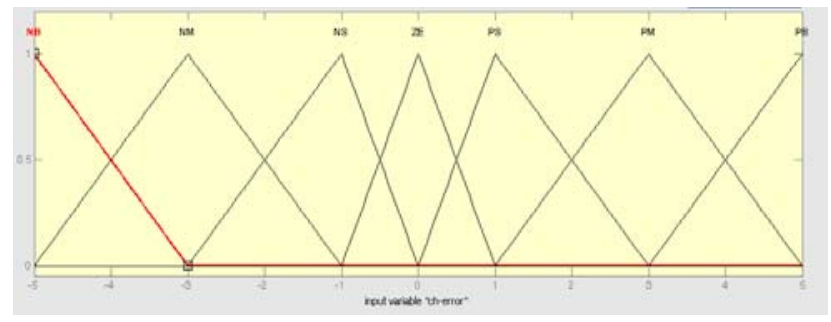

Fig. 16. Membership function of change of error (CE).

Fig. 17 illustrates the fuzzy set of the output which contains 7 Triangular memberships.

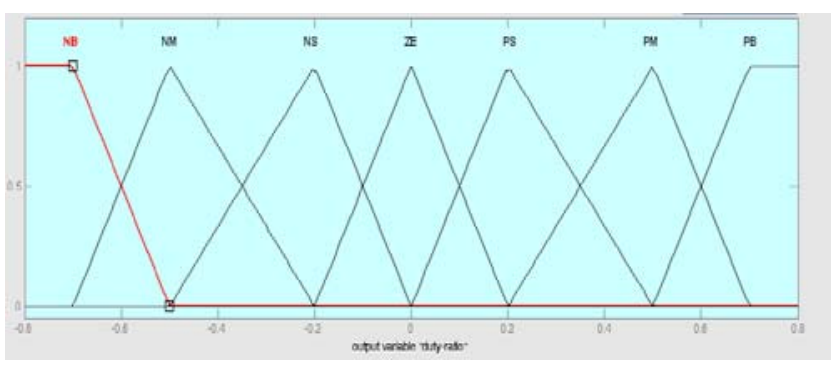

Fig. 17 Membership function of duty ratio (D).

\section{2) Control rule base}

The knowledge base defining the rules for the desired relationship is between the input and output variables in terms of the membership functions illustrated in Table II. The control rules are evaluated by an inference mechanism, and represented as a set of:

Rule1: IF Error is NL and Change of Error is ZE THEN the output is NS.

The linguistic variables used are:

NB: Negative Big, NM: Negative Medium, NS: Negative Small, ZE: Zero, PS: Positive Small, PM: Positive Medium, PB: Positive Big.

TABLE II: CONTROL RULE BASE FOR MPPT FUZZY CONTROLLER.

\begin{tabular}{|c|c|c|c|c|c|c|c|}
\hline$E \downarrow d$ & NB & N & NS & ZE & PS & PM & PB \\
\hline NB & ZE & ZE & ZE & NB & NB & NB & NB \\
\hline NM & ZE & ZE & ZE & NM & NM & NM & NM \\
\hline NS & NS & ZE & ZE & NS & NS & NS & NS \\
\hline ZE & NM & NS & ZE & ZE & ZE & PS & PM \\
\hline PS & PM & PS & PS & PS & ZE & ZE & PS \\
\hline PM & PM & PM & PM & PM & ZE & ZE & ZE \\
\hline PB & PB & PB & PB & PB & ZE & ZE & ZE \\
\hline
\end{tabular}

\section{3) Defuzzification}

The defuzzification uses the centre of gravity to compute the output of this FLC which is the duty cycle (D):

$$
D=\frac{\sum_{j=1}^{n} \mu\left(d_{j}\right)-d_{j}}{\sum_{j=1}^{n} \mu\left(d_{j}\right)}
$$




\section{MPPT FLC SimULATION ON MATLAB/SIMULINK}

Before applying the fuzzy controller on PV, modelling of PV must be set-up.

\section{A. $P V$ modelling for Simulation}

The equations from 1 to 4 used for generating the current by PV array are represented by MATLAB/SIMULINK as shown in Fig. 18.

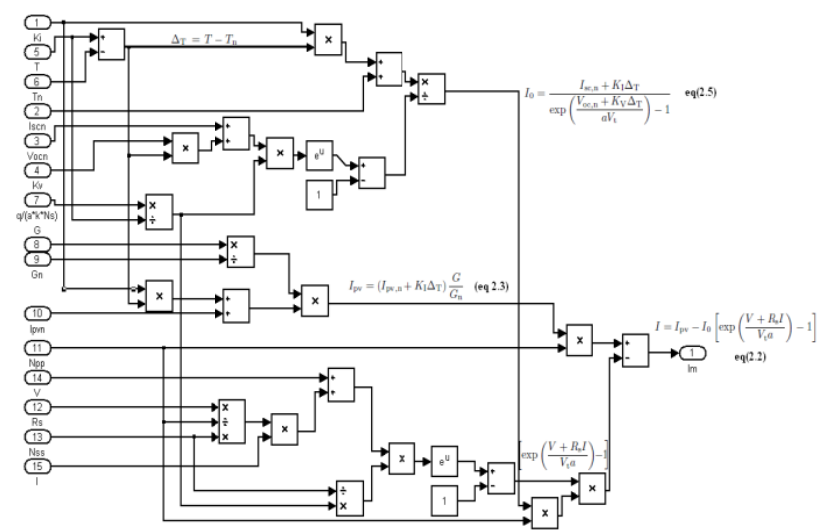

Fig. 18. Modeling of the current generated by PV array Simulink.

\section{B. MPPT Matlab Simulation}

1) GUI interface for PV model

The PV model have a large number of parameters, so a graphical user interface GUI is set-up for entering the parameters of any array model using information from its datasheet as shown in Fig. 19.

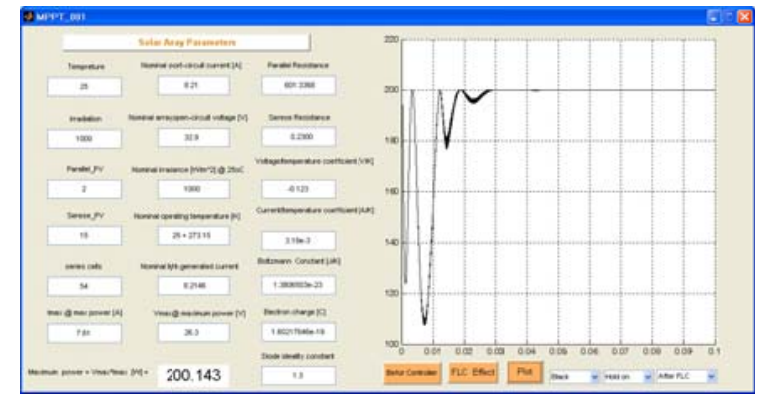

Fig. 19. GUI for entering parameters of any array from its datasheet.

\section{2) Control signal generation in simulation}

Fig. 20 shows equations 5 and 6 are represented, to generate Error and Change in error signals as inputs for FLC.

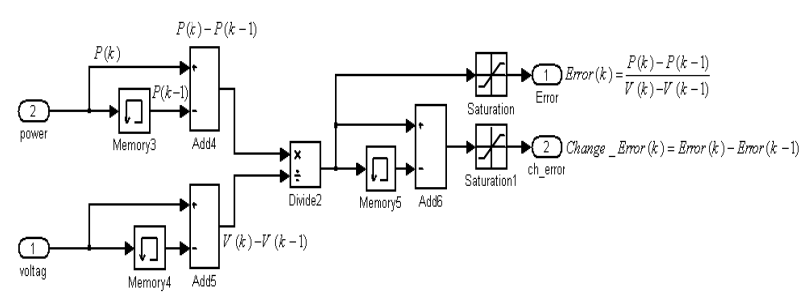

Fig. 20. Generating the error and change in error signals.

\section{3) Fuzzy logic controller simulation}

The designed fuzzy controller now can connected between PV module and DC-to-DC converter module to tracking the MPP, as shown in Fig. 21.

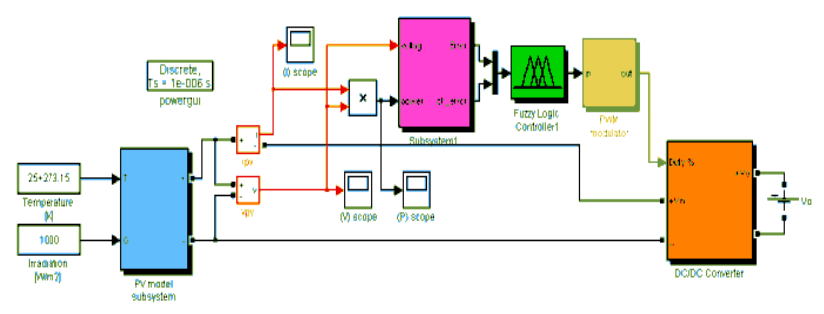

Fig. 21. Controlling the PV power using FLC.

The parameters information of PV array is entered by GUI interface from the KC200GT solar array datasheet:

Nominal short-circuit voltage [A]: Iscn $=8.21$

Nominal array open-circuit voltage $[\mathrm{V}]$ : Vocn $=32.9$

Array current at maximum power point [A]: $\operatorname{Imp}=7.61$

Array voltage at maximum power point $[\mathrm{V}]: \mathrm{Vmp}=26.3$

Voltage/temperature coefficient $[\mathrm{V} / \mathrm{K}]: \mathrm{Kv}=-0.123$

Current/temperature coefficient $[\mathrm{A} / \mathrm{K}]: \mathrm{Ki}=3.18 \mathrm{e}-3$

Nunber of series cells: $\mathrm{Ns}=54$

Nominal irradiance $\left[\mathrm{W} / \mathrm{m}^{\wedge} 2\right]$ at $25 \mathrm{oC}: \mathrm{Gn}=1000$

Nominal operating temperature $[\mathrm{K}]: \mathrm{Tn}=25+273.15$

Boltzmann Constant $[\mathrm{J} / \mathrm{K}]: \mathrm{k}=1.3806503 \mathrm{e}-23$

Electron charge Constant $[\mathrm{C}]: \mathrm{q}=1.60217646 \mathrm{e}-19$

Diode ideality constant: $\mathrm{a}=1.3$.

Fig. 22 shows the effect of the FLC controller on the PV power, since it becomes constant at the maximum value (200.14 W) after a small stilling time.

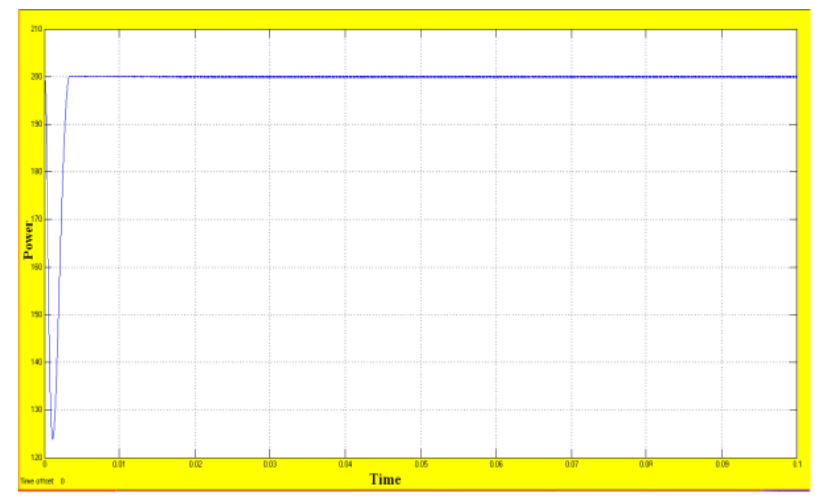

Fig. 22. Controller effect on the power.

The results of applying the FLC on PV system to track the MMP is compared with a conventional controller applied on the same system by Villalva [15]. This controller is perturbation and observation controller. The principle of this controller is done by changing the PWM duty cycle (D) and observing the effect on the output PV power; this can be detailed as follows:

- When $\mathrm{dp} / \mathrm{dv}>0$, the voltage is increased, this is done through $\mathrm{D}(\mathrm{k})=\mathrm{D}(\mathrm{k}-1)+\mathrm{C}$.

(C:incrementation step),

- When $\mathrm{dp} / \mathrm{dv}<0$, the voltage is decreased through $\mathrm{D}(\mathrm{k})=\mathrm{D}(\mathrm{k}-1)-\mathrm{C}$.

Fig. 23 shows the effect of the two controller's perturbation and observation and FLC controller on the same PV power. The response of FLC is better than the response of the perturbation and observation controller since it take more settling time. Other drawback point in perturbation and observation controller is that it depends on knowing the value of the voltage at the MPP (Vm). 


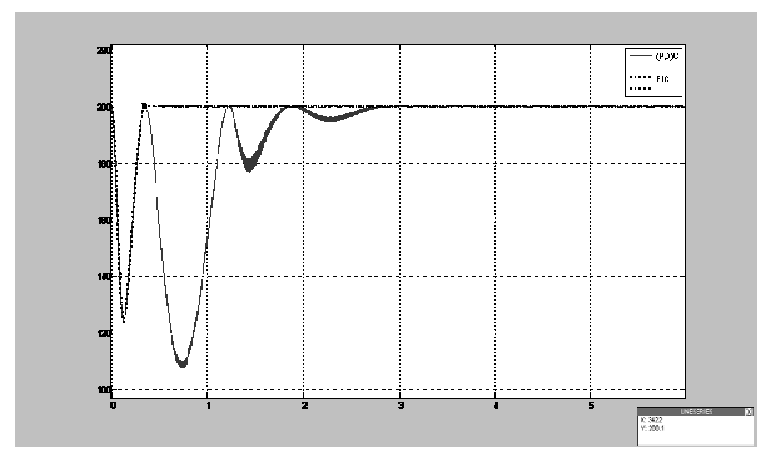

Fig. 23. The Effect of the Conventional Controller and FLC Controller on the PV Power.

\section{EXPERIMENT RESULTS}

This section shows the usefulness of proposed maximum power point tracking controller by fuzzy controller.In the first, the fuzzy logic controller for MPPT will implement on the FPGA card. Then, the DC-to-DC implemented and connected with the FPGA.

\section{A. Implementing Fuzzy Logic Controller on an FPGA}

The fuzzy logic controller designed earlier is implemented on Xilinx XC3S700AN FPGA card as shown in Fig. 9. Fig. 24 shows the RTL schematic diagram in Xilinx software RTL Viewer to view a schematic representation for the FLC and other components after implementing it on Xilinx ISE 11.1 software. The inputs of the controller are the error and change in error as in (5) and (6). The output of the controller is connected with a PWM module designed on the FPGA. The PWM frequency of the modulating signal is about $3 \mathrm{KHz}$, this value calculated by experiment. A 14-bit counter runs at the clock of FPGA $=50 \mathrm{MHz}$ completes cycles at a rate $50 \mathrm{M} / 214 \approx 3 \mathrm{KHz}$. In this case, each level in an 8-bit modulating signal corresponds to $214 / 256=26$ clock pulses.

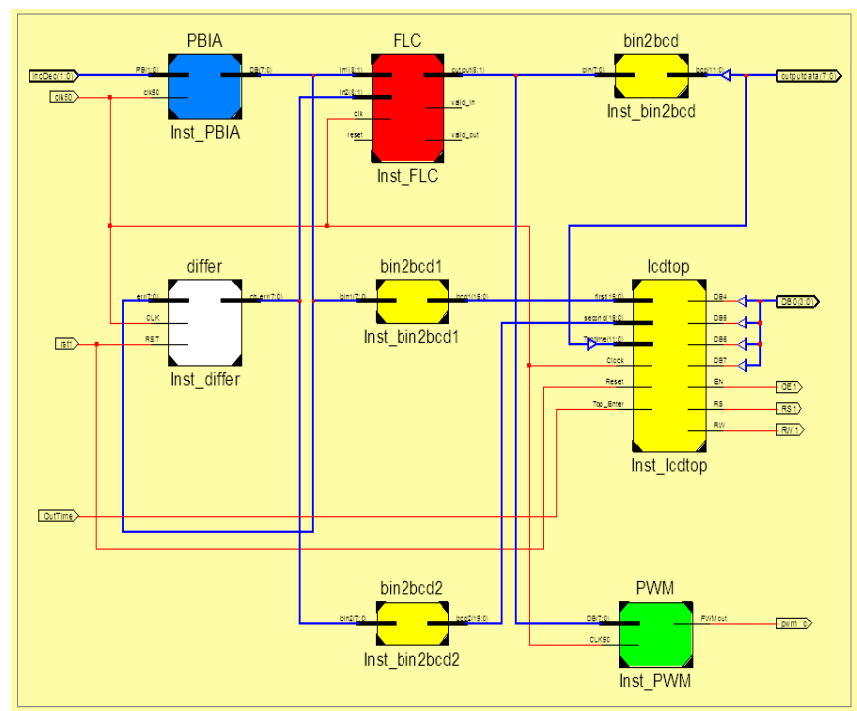

Fig. 24. RTL schematic diagrams for the FLC with other blocks

The output of the PWM is examined using the oscilloscope by changing the values of the FLC and observe the change in the duty cycle of the PWM output as shown in Fig. 25.

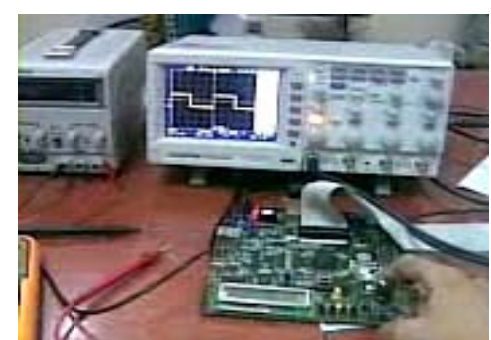

Fig. 25. Examining PWM output.

\section{B. Implementing the DC-to-DC Converter}

The DC-to-DC converter is implemented and is connected with FPGA card. The circuit included parts of Buck components such as controllable switch (IRF740A), inductor and capacitor, PIC16F877 microcontroller as an ADC, IR2110 Half Bridge Driver, optocubler isolator (6N137), and other basic components. In order to maintain output voltage, controller will be operated in feedback circuit. The output of the DC-to-DC converter is examined using the oscilloscope by changing the values of the FLC inputs as an open loop and observe the change in the duty cycle of the PWM output and the change in the converter output as shown in Fig. 26.

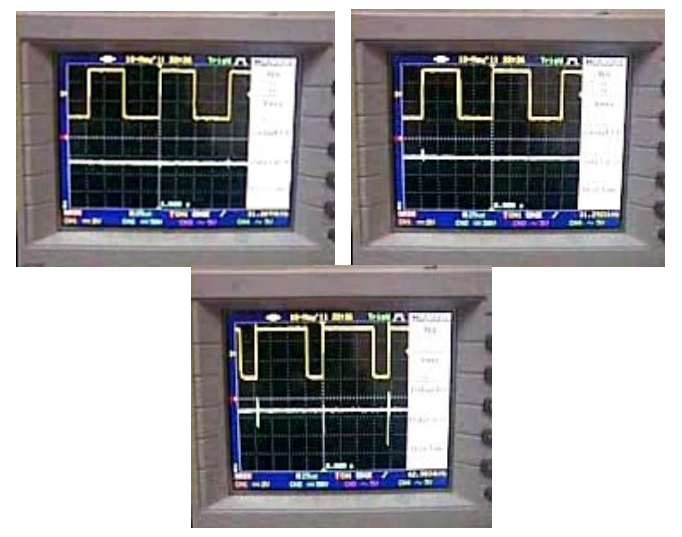

Fig. 26. Examining PWM output with open loop controller.

After adding the close loop FLC by changing the value of the input voltage to the DC-to-DC converter, the duty cycle value is constant for each input and the output voltage is constant for all DC-to-DC input voltages as shown in Fig. 27.

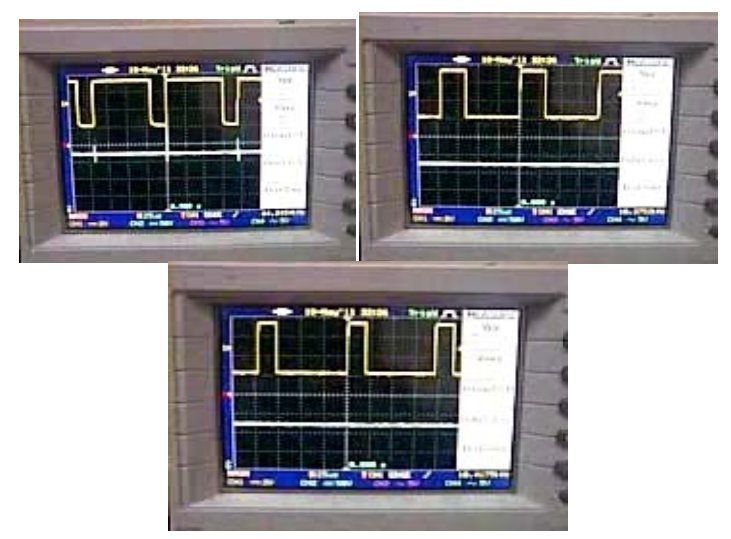

Fig. 27. Examining the PWM output with close loop controller. 


\section{Implementing the two FLC on an FPGA}

Fig. 28 shows the RTL schematic diagram in Xilinx software RTL Viewer to view a schematic representation for the last two FLC and other components after implementing it on Xilinx_ISE 11.1 software.

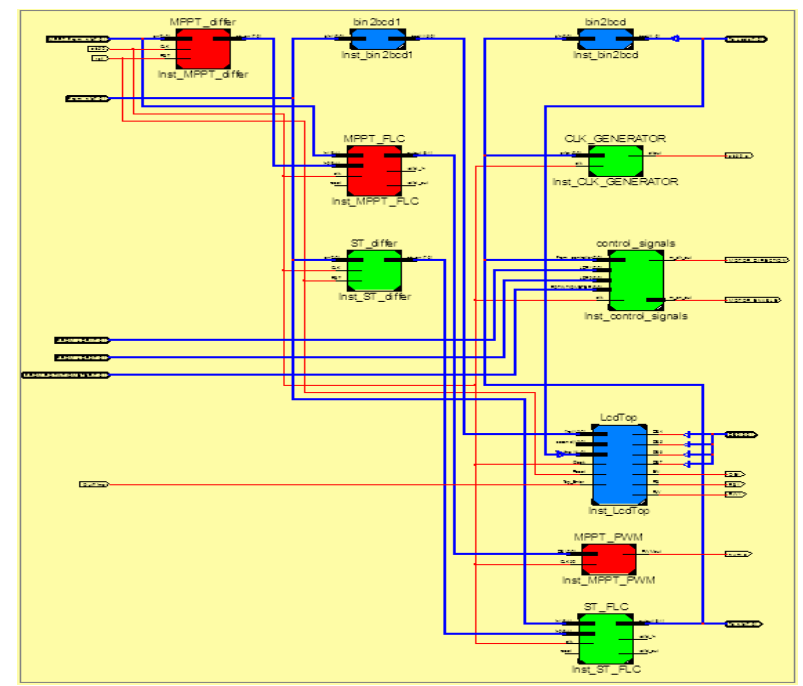

Fig. 28. RTL schematic diagrams for Two FLC with other blocks.

The experimental data of the solar generating power system are measured outdoors by measuring the voltage and current for the same load in each hour and calculating the average value for all days. Fig. 29 represents the power data.

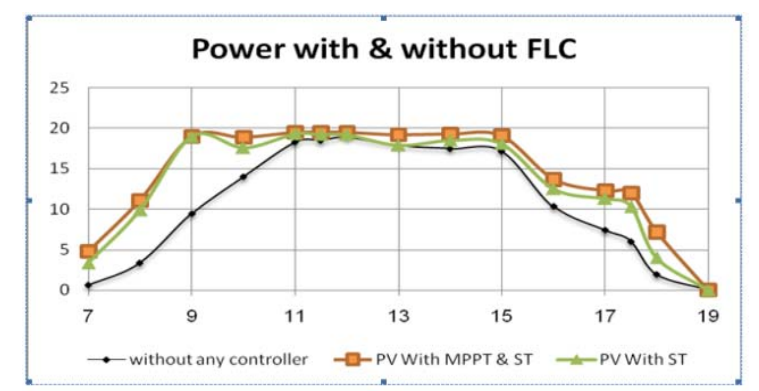

Fig. 29. Power generation comparison with and without using ST and

$$
\text { MPPT Controller. }
$$

As Shown in Fig. 29 the efficiency with two controllers MPPT and sun tracker solar tracking system is 33\% higher than the efficiency without controllersMPPT and sun tracker system.

\section{CONCLUTION}

In this paper, two fuzzy logic controllers are fabricated on the same modern FPGA card to increase the energy generation efficiency of tracking controller received from solar cells. By implementing a sun tracker controlled using fuzzy logic controller to keep the PV panel pointing toward the sun by using a stepper motor.Sun tracking generating power system is designed and implemented in real time. MPPT using fuzzy control increases the energy generation efficiency of the solar cells. The proposed method is done by implementing a MPPT controlled by FLC and using buck
DC-to-DC converter to keep the PV output power at the maximum point all the time. Both controllers are tested using Matlab/Simulink program, and the results was compared with a perturbation and observation controllers applied on the same system. The proposed solar tracking power generation fuzzy controller is able to track the sun light automatically. The comparison shows that the fuzzy logic controller is better in response and don't depend on knowing any parameter of PV panel. The information required for fuzzy control is only generating power, therefore, the hardware is simple and the cost of this system is inexpensive.

\section{REFERENCES}

[1] Photovoltaic Project Analysis, Clean Energy Decision Support Centre, Minister of Natural, Resources Canada, 2001 - 2004.

[2] Z. Salameh and D. Taylor, "Step-up Maximum Power Point Ikacker for Photovoltaic Arrays," Solar Energy, vol. 44, no. 1, pp. 57-61, 1990.

[3] T. Ohnishi and S. Takata, "Comparisons of maximum power tracking strategy of solar cell output and control characteristics using step up/down chopper circuit," Trans. IEEE, vol. 3, no. 112-D, pp. 250/257, 1992.

[4] K. K. Tse, M. T. Ho, H. Chung, and S. Y. Hui, "A novel maximum power point tracker for pv panels using switching frequency modulation," IEEE Transactions on Power Electronics, vol. 17, no. 6, November 2002.

[5] M. A. S Masoum and M. Sarvi, Design, simulation and construction of a new fuzzy-based maximum power point tracker for photovoltaic applications.

[6] C. Y. Won, D. H. Kim, S. C. Kim, W. S. Kim, and H. S. Kim, "A new maximum power point tracker of photovoltaic arrays using fuzzy controller," in Proc. the IEEE Power Elec. Specialist Temp Conference, pp. 396-403, 1994.

[7] J. L. Castro, "Fuzzy logic controllers are universal approximators," IEEE Transactions on System, Man, and Cybernetics, vol. 25, no. 4, pp. 629-635.

[8] L. X. Wang, "Stable adaptive fuzzy control of nonlinear systems," IEEE Trans. Fuzzy systems, vol. 1, no. 2, pp. 146-154, 1993.

[9] W.i Zhao, B. H. Kim, A. C. Larson, and R. M. Voyles, "FPGA implementation of closed loop control system for small scale robot," in Proc. International conference on advanced robotics-ICAR 05, pp. 70- 77, 2005.

[10] Y. F. Chan, M. Moallem, and W. Wang, "Efficient implementation of PID control algorithm using FPGA technology," in Proc. 43rd IEEE Conference on Decision and Control, December 2004.

[11] T. Runghim, T. Intajag, and S. Krongratana, "Fuzzy logic PID controller based on FPGA for process contro," IEEE, vol. 2, no. 11, pp. 1495- 1500, 2004.

[12] G. Sakthivel, T. Anandhi, and S. Natarajan, "Real time implementation of a fuzzy logic controller on fpga using vhdl for dc motor speed control," International Journal of Engineering Science and Technology, vol. 2, no. 9, pp. 4511-4519, 2010.

[13] H. A. Yousef, "Design and Implementation of a Fuzzy Logic 100 Computer-Controlled sun Tracking System photovoltaic Systems," IEEE, 1999.

[14] F. Huang, D. Tien, and J. Or, "A microcontroller based automatic sun tracker combined with a new solar energy conversion unit," IEEE 1998.

[15] P. Y. Vorobiev, J. G. Hemhdez, and Y. V. Vorobiev, "Optimization of the solar energy collection in tracking and non- tracking photovoltaic solar system," in Proc. IEEE 2004 1st International Conference on Electrical and Electronics Engineering.

[16] S. Gene and J. Monroe, "Robust fuzzy controllers using FPGAs," NASA LaRC, 2006.

[17] B. Singh, R. Goyal, R. Kumar, and R. Singh, "Design and VLSI implementation of fuzzy logic controller," (IJCNS) International Journal of Computer and Network Security, vol. 1, no. 3, December 2009.

[18] R. Patel, Wind and solar power systems, CRC Press LLC, 1999

[19] M. Villalva, J. Gazoli, and E. Ruppert, "Modeling and circuit-based simulation of photovoltaic arrays," IEEE Transactions on Power Electronics, vol. 24, no. 5, May 2009.

[20] M. E. Ashry, Renewables 2010 global status report, Paris: REN21 Secretariat, Copyright Deutsche (GTZ) GmbH, 2010. 
[21] M. A. Cheikh and S. C. Larbes, "Maximum power point tracking using a fuzzy logic control scheme," September 2007.

Basil Hamed is an associate professor of Electrical Engineering Department, Islamic University of Gaza, Palestine, since 1999. He has Bachelor Degree in Electrical Engineering from New Mexico State University, NM. USA in the year of 1989 , he received Master degree from University of New Orleans, La. USA in the year of 1992, and earned his PhD (Fuzzy Control System) from New Mexico State University, NM USA in the year 1999. He has 15 years of teaching experience and has published many papers in national and international journals. His fields of interest include Control Systems, Fuzzy Control, Simulation and Modelling, FPGA, Genetic Algorithm, SCADA System, Signal and Image Processing.

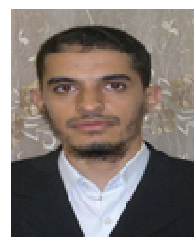

MohmmadEl-Moghany was born on February 25, 1981. He received the B.Sc. and M.SC. Degrees from Islamic University of Gaza, in 2001 and 2011, respectively. His research interests include Fuzzy Logic Control, Renewable Energy, FPGA, Optimal Control, Genetic Algorithm, Microcontroller, Nonlinear Control, and VHDL. 